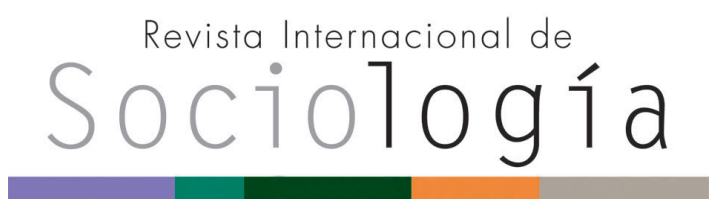

Revista Internacional de Sociología RIS vol. 73 (3), e017, septiembre-diciembre, 2015, ISSN-L:0034-9712

DOI: http://dx.doi.org/10.3989/ris.2015.73.3.e017

\section{BIENESTAR Y PATRONES RESIDENCIALES DE LA POBLACIÓN QUE ENVEJECE Y NO CONVIVE EN PAREJA. Europa occidental, 2004-2011 ${ }^{1}$}

WELLBEING AND LIVING ARRANGEMENTS OF AGEING POPULATION WITH NO CORESIDENT PARTNER. Western Europe, 2004-2011

\author{
Pau Miret Gamundi \\ Centre d'Estudis Demogràfics - Universitat Autònoma de Barcelona, España \\ pmiret@ced.uab.cat \\ PILAR ZUERAS \\ Centre d'Estudis Demogràfics - Universitat Autònoma de Barcelona, España \\ pzueras@ced.uab.es
}

Como citar este artículo / Citation: Miret Gamundi, P. y Pilar Zueras. 2015. «Bienestar y patrones residenciales de la población que envejece y no convive en pareja. Europa occidental, 2004-2011». Revista Internacional de Sociología, DOI: http://dx.doi.org/10.3989/ris.2015.73.3.e017

Copyright: ( 2015 CSIC. Este artículo de acceso abierto distribuido bajo los términos de la licencia Creative Commons Attribution-Non Commercial (by-cn) Spain 3.0.

Recibido: 20/12/2013. Aceptado: 15/03/2015

Publicación online: 03/11/2015

\title{
RESUMEN
}

Este trabajo analiza la población mayor de 65 años que no convive en pareja en diez países europeos que participaron en las cuatro ediciones de la Survey of Health, Ageing and Retirement in Europe, de 2004/5 a 2010/1. Mediante la regresión logística para panel se analiza la ratio entre convivir con otras personas y vivir solo (sin considerar a la población mayor que se institucionaliza). Controlando por edad, sexo, país de residencia y ciclo de observación, se presenta el efecto del nivel educativo, número de hijos, limitaciones para las actividades de la vida diaria y nivel de renta. Aparece con

claridad la división regional, siendo el área con la menor probabilidad de vivir solo el sur de Europa, la intermedia la Europa central y la de mayor los países nórdicos. La corresidencia está asociada a la pérdida de autonomía funcional, al nivel de instrucción y al número de hijos. En contraste, no se ha encontrado una vinculación significativa con el nivel de renta.

\section{Palabras Clave}

Europa; Familia; Formas de convivencia; Independencia residencial; Personas mayores; Salud.

1 Este artículo utiliza datos de SHARE ciclo 1 y 2 versión 2.5.0. publicados el 24 de Mayo de 2011, SHARELIFE versión 1 publicada el 24 de Noviembre de 2010, y SHARE ciclo 4 versión 1.1.1. de 28 de Marzo de 2013. La recolección de datos SHARE fue fundada en primera instancia por la Comisión Europea a través del $5^{\circ}$ programa marco (proyecto QLK6-CT-2001-00360 en el programa temático Calidad de Vida), a través del $6^{\circ}$ programa marco (proyecto SHARE-I3, RII-CT-2006-062193, COMPARE, CIT5-CT-2005-028857, y SHARELIFE, CIT4-CT-2006-028812) y a través del $7^{\circ}$ programa marco (SHARE-PREP, $n^{\circ} 211909$, SHARE-LEAP, $n^{\circ} 227822$ y SHARE M4, $n^{\circ}$ 261982). Se agradecen también los fondos adicionales del Instituto Nacional sobre envejecimiento de los EE.UU (U01 AG09740-13S2, P01 AG08291, P30 AG12815. R21 AG025169, Y1-AG-4553-01, IAG BSR0611 y OGHA 04-064) y del Ministerio de Educación e Investigación alemán, así como de diversas fuentes nacionales (véase www. hare-project.org para una lista completa de las instituciones financiadoras.

Una versión preliminar de este artículo fue presentada al XI Congreso Español de Sociología, al grupo de trabajo sobre Sociología de la Edad y Ciclo vital, coordinado por Lourdes Pérez Ortiz. Los autores agradecen los valiosos comentarios recogidos en este foro.

El artículo se inscribe dentro del proyecto "Acicates en la prolongación de la vida laboral: salud, formación y formas de convivencia", coordinado por los Dres. Pau Miret y Amand Blanes, financiado por el Ministerio de Economía y Competitividad dentro del Plan Nacional de I+D+i, bajo la referencia CSO2013-48042-R. 


\section{Abstract}

This paper analyses the population aged 65 and over who do not live with a partner, in ten European countries participating in the four editions of the "Survey of Health, Ageing and Retirement in Europe", from 2004/5 to 2010/1. Logistic regression for panel data is used to analyse the ratio between living with others and living alone (not considering institutionalised people). Controlling for age, sex, country of residence and observation wave, it shows the effect of educational level, number of children, limitations in activities of daily living and level of income. A clear regional

\section{INTRODUCCIÓN}

Las dinámicas de población, en especial el descenso de la fecundidad y el incremento de la esperanza de vida, han provocado un rápido envejecimiento demográfico cuyas implicaciones socioeconómicas lo han situado en el centro del debate político en Europa. La proporción de mayores de 65 años, que en 1990 era de 13,7 \% (EU27), se ha elevado a $17,4 \%$ en 2010 y seguirá en aumento debido a la llegada a esas edades de las generaciones del baby boom. Con el fin de suavizar el impacto económico y social de dichos cambios, se ha desarrollado un discurso político bajo el lema de envejecimiento activo que pretende promover el empleo, la participación social y la autonomía de los mayores para así fomentar entre esta población un envejecimiento saludable y una vida independiente.

Se aborda en este trabajo la autonomía residencial de las personas mayores a través del análisis de sus formas de convivencia en algunos países europeos que presentan notables diferencias en cuanto a sus patrones residenciales. El aumento de la longevidad ha pospuesto el momento de la viudedad prolongando los años de vida en pareja, lo que favorece la independencia residencial incluso en situaciones de deterioro de la salud de uno de los cónyuges. Si bien es innegable que el modelo de convivencia más común entre la población adulta es el residir en pareja, se ha estudiado poco el modelo de hogar de quienes no disponen de ella, de manera que teóricamente pueden elegir si residen con otras personas o en solitario. Otro elemento a tener en cuenta es el alcance de la institucionalización, muy diferente entre países. De hecho, si consideráramos la institucionalización como alternativa a vivir con otras personas podemos prescindir de los países del sur, pues a nivel agregado esta alternativa apenas existe. En los demás países la institucionalización juega un papel parecido, por lo que cabe preguntarse hasta qué punto el hecho de convivir con otras personas en el sur de Europa no se debe a la ausencia real de la posibilidad de optar por la institucionalización en caso de necesidad, al no existir una oferta accesible de este servicio. Al centrarnos solo en quienes no conviven en pareja, la pregunta de division arises, being southern Europe the area with the lowest probability of living alone, central Europe in an intermediate position and the highest in Nordic countries. Coresidence is associated with the loss of functional autonomy, educational attainment and number of children. In contrast, a significant link with income level has not been found.

\section{KeYWORDS}

Europe; Family; Health; Independent Dwelling; Living Arrangements; Older Persons. investigación es la siguiente ¿la mayor o menor propensión a convivir con otras personas en relación a vivir solo es cultural o existen factores estructurales o coyunturales que explican estas substanciales diferencias? Avanzamos que la respuesta a esta pregunta apunta a que la distancia cultural entre países que se observa desde el principio del análisis resiste prácticamente inmutable todas las pruebas a las que se la somete.

Esta investigación se centra en quienes no conviven en pareja ni han sido institucionalizados, preguntándose por las diferencias en las características personales y contextuales de quienes residen acompañados en relación a quienes lo hacen en solitario. Para ello se han utilizado los datos provenientes de los cuatro ciclos disponibles hasta el momento de la Encuesta de Salud, Envejecimiento y Jubilación en Europa (Survey of Health, Ageing and Retirement in Europe, SHARE), y se han seleccionado los países que participaron en todas ellas. Concretamente, analiza el patrón residencial de la población de 66 a 95 años sin pareja corresidente en diez países de Europa occidental: Austria, Francia, Alemania, Suiza, Bélgica, Holanda, Dinamarca, Suecia, Italia y España.

\section{REVISIÓN BIBLIOGRÁFICA}

Diversos estudios han abordado el análisis comparativo de la solidaridad intergeneracional en Europa en cuanto al intercambio de recursos, ya sean económicos o de espacio (convivencia), y la provisión de cuidados. Los mecanismos de solidaridad intergeneracional en el seno de la familia parecen responder a diferentes modelos regionales graduados de norte a sur (Kohli, Künemund y Lüdicke 2005; Albertini y Kohli 2013). En los países del sur se da una mayor frecuencia de contactos entre los padres y los hijos adultos (Hank 2005) y la convivencia en un mismo hogar o en un hogar independiente en el mismo edificio es también más común (Kalmijn y Saraceno 2008; Isengard y Szydlik 2012). Asimismo, se dan patrones diferenciados respecto a las transferencias económicas intergeneracionales, que son más habituales pero de menor intensidad 
en los países del norte que en los del sur (Albertini, Kohli y Vogel 2007). En definitiva, en los países nórdicos las transferencias económicas complementan las percibidas desde el Estado, mientras que en los países meridionales la solidaridad se da principalmente a través de la corresidencia y en raras ocasiones las transferencias económicas traspasan los límites del hogar, quedando los países continentales en una situación intermedia con un sistema mixto donde se suman corresidencia y transferencias monetarias (Albertini y Kohli 2013).

Las formas de convivencia de los mayores podrían estar asociadas a preferencias culturales más «familiaristas» 0 individualistas sobre la responsabilidad familiar en el cuidado y provisión de asistencia a la población anciana (ibíd.). Si bien, las distintas estrategias de solidaridad parecen responder más a las carencias institucionales que a la predisposición de los hijos a atenderlas (Kalmijn y Saraceno 2008) y configurarse en función de las necesidades cubiertas 0 insatisfechas por los respectivos estados de bienestar (Daatland y Lowenstein 2005). Estas carencias, junto con los patrones residenciales -con mayor prevalencia de la convivencia intergeneracional en los países del sur-, así como una menor tasa de ocupación entre las generaciones femeninas más mayores, favorecen también patrones de cuidado diferenciados entre norte y sur. Mientras en los países del sur los cuidados generalmente son relegados a pocas personas dentro de la familia y con mayor intensidad y dedicación, en los países del norte y centro los cuidados informales a los mayores implican a más personas del círculo familiar o social; de tal manera que las personas mayores viviendo solas tienen mayores probabilidades de recibir ayuda que en los países del sur (Attias-Donfut, Ogg y Wolf 2005).

En todos los países europeos se ha detectado una tendencia a vivir en solitario, manteniéndose la distancia entre patrones regionales (Pampel 1992; Palloni 2001): así, aunque la mayoría de los que no conviven en pareja viven solos, en el norte está más extendida la institucionalización, en especial en las edades a partir de 80 años, (Laferrère et al. 2013, Fernández Carro 2013: 103-14) y la corresidencia con hijos u otras personas fuera de la pareja es más frecuente en el sur de Europa (de Jong Gierveld, de Valk, y Blommesteijn 2001; Delbès, Gaymu y Springer 2006; Zueras y Miret 2013). En particular en España se viene observando entre los mayores un aumento de la vida en solitario en detrimento de la corresidencia con hijos u otras personas fuera de la pareja (Pérez Ortiz 2006; Abellán et al. 2007). En concreto, el censo de 1991 recogía un 16,2 $\%$ de solitarios entre la población de 65 o más años y el de 2001 un 19,6 \%, incremento que López Doblas (2005) consideró que no se debía a la erosión de la solidaridad intergeneracional, sino a una mejora en la salud y en el bienestar material de los mayores. En el mismo sentido, Zueras y Miret (2013) confirman que parte de este aumento se debe a un mayor acceso a las pensiones entre los mayores. Asimismo se constata un cambio de actitud entre los mayores españoles que, mientras las condiciones de salud lo permitan, apelan a su independencia residencial para mantener la autonomía en la gestión de su vida cotidiana (López Doblas 2013).

La mayor longevidad lleva a una extensión de la vida en pareja, pero el diferencial de supervivencia entre sexos supone una mayor probabilidad de viudedad entre las mujeres, lo que explica que ellas vivan menos en pareja que los varones. Por ejemplo, en Europa en 2000 mientras que una de cada cinco mujeres mayores de 74 años convivía en pareja, entre los hombres esta ratio era de dos de cada tres (Delbès, Gaymu y Springer 2006). Pero en ausencia de pareja, la vida en solitario es la más común para ambos sexos: así, tomando el estado civil como aproximación al hecho de tener pareja, se observa una mayor proporción de hogares unipersonales entre los viudos y divorciados que entre los solteros y los casados (lo que no deja de ser una explicación endógena, pues los casados residen prácticamente siempre con su cónyuge), aunque las proporciones difieren entre el norte y el sur de Europa (de Jong Gierveld, de Valk, y Blommesteijn 2001; Delbès, Gaymu y Springer 2006). Se ha observado que el divorcio afecta negativamente a la relación entre padres e hijos a largo plazo reduciendo la intensidad de las relaciones intergeneracionales también en la vejez (Albertini y Garriga 2011). En este sentido, se percibe una menor propensión a vivir con hijos entre los divorciados (Aquilino 1990; Pezzin y Schone 1999, Kalmijn y Saraceno 2008), así como una menor probabilidad de vivir solos y mayor propensión a residir en instituciones de los solteros (Delbès, Gaymu y Springer 2006).

La edad también está relacionada fuertemente con las formas de convivencia de los mayores, pues a partir de los 75 años la vida independiente disminuye con la edad. Los motivos que se aducen son variados, así los relativos a la mala salud o a la limitación funcional (Pezzin y Schone 1999; Festy y Rychtarikova 2008; Zueras y Ajenjo 2010). Sea por fragilidad o por soledad, los más ancianos viven más frecuentemente en instituciones o cohabitan con hijos u otras personas. Así, a partir de los 75 años la pérdida de independencia residencial es una situación cada vez más frecuente con la edad entre las personas que no tienen cónyuge, incluso a igual estado de salud autodeclarado.

En cualquier caso, la pérdida de capacidad funcional erosiona la independencia residencial y aparece asociada a la convivencia con otros 0 a la institucionalización (Bishop 1986; Speare, Avery y Lawton 1991; Mutchler y Burr 1991; Worobey y Angel 1992; Mickus, Stommel y Given 1997; Zueras y Ajenjo 2010). Sin embargo, a nivel europeo se han observado particularidades según regiones. Así, la pérdida de capacidad funcional, y en especial cuando no se dispone de pareja, reduce la probabilidad de 
vivir solo en los países del sur de Europa, donde la provisión de servicios sociales es menor, pero no en los países del norte (lacovou 2000), donde la institucionalización es una opción más frecuente en estos casos (Delbès, Gaymu y Springer 2006; Laferrère et al. 2013).

En el caso de vivir acompañado en la vejez, lo más común es hacerlo con los hijos. Algunos estudios observan que un mayor número de hijos aumenta la probabilidad de pasar de vivir solo a corresidir con alguno de ellos, frente a convivir con otras personas o institucionalizarse (Spitze, Logan y Robinson 1992). En Europa este efecto positivo solo se aprecia en los países del norte donde la movilidad interregional es mayor (lacovou 2000); por otro lado también se ha observado que en España haber tenido un solo hijo favorece la convivencia con él en la vejez después de la viudedad (Zueras 2014).

Finalmente, también las características socioeconómicas son discriminantes en las formas de convivencia de los adultos mayores. Así, un elevado nivel de instrucción o altos ingresos están asociados a una mayor independencia residencial (Palloni 2001). Aunque es cierto que un nivel educativo elevado está relacionado con una mayor esperanza de vida libre de discapacidad (Robine, Romieu, y Cambois 1999), se observa el mismo efecto entre los mayores de 74 años con discapacidad: la corresidencia con otras personas diferentes de la pareja es menos frecuente también entre los que tienen un mayor nivel educativo, con independencia de su estado civil (Festy y Rychtarikova 2008). Por otro lado, aunque se han encontrado evidencias de que los recursos económicos determinan las formas de convivencia y favorecen el mantenimiento de la independencia residencial (Bishop 1986; Mutchler y Burr 1991), la relación positiva de los ingresos con la vida en solitario no es siempre lineal, pues algunos estudios muestran que el nivel económico es discriminante solo para los cuartiles intermedios, lo que sugiere que la renta tiene efecto únicamente alrededor de un umbral que permite o no el mantenimiento de la vida independiente (lacovou 2000).

Más allá de las características individuales, los patrones residenciales de los adultos mayores responden no solo a sus necesidades y oportunidades sino a las de sus hijos; la convivencia es más frecuente con hijos divorciados, viudos, desempleados, o que siguen estudiando (Albertini y Kohli 2013). Las formas de convivencia están a su vez condicionadas por la influencia de cambios coyunturales como el devenir de una crisis económica. Una comparativa europea muestra que la mayor propensión a vivir con los hijos en la vejez está relacionada con indicadores macroeconómicos, de manera que esta forma de convivencia parece aumentar como respuesta a la incertidumbre económica (Isengard y Szydlik 2012).

El presente artículo parte de la hipótesis de que en ausencia de pareja corresidente y siempre que las condiciones económicas y de salud lo permitan, la probabilidad de residir en un hogar unipersonal es significativamente superior a la de vivir con otras personas, sean o no estas familiares. Esta declaración inicial se confirmará si, para empezar, encontramos que la población vive más acompañada y menos en solitario cuanto más años va cumpliendo, pues con la edad disminuye la autonomía personal (Hipótesis 1). También habría que constatar si en tiempos de crisis económica se reduce la proporción de solitarios, en comparación con los momentos de bonanza, pues, mientras que las dificultades fuerzan a compartir residencia, los buenos tiempos incrementan la libertad para escoger el tipo de hogar en que se vive (Hipótesis 2). Igualmente, esperamos comprobar que a mayor nivel educativo y de renta, mayor residencia en un hogar unipersonal, lo que se explicaría también por la mayor capacidad de elección que estos otorgan (Hipótesis 3). Finalmente, consideramos la disponibilidad de hijos como principal recurso convivencial en la vejez, en especial cuando las condiciones de salud y funcionalidad de los padres requieren de asistencia; de manera que se espera que el mayor número de hijos aumente la probabilidad de residir con alguno de ellos (Hipótesis 4). Se espera que las variables individuales económicas y de limitación funcional erosionen el efecto del nivel educativo y de la edad respectivamente. De un lado, se supone que un mayor nivel de ingresos favorece la vida en solitario; mientras que, una mayor limitación en las actividades básicas (ABVD) o instrumentales (AIVD) de la vida diaria aumenta la probabilidad de convivir con otras personas, con mayor intensidad en el sur.

\section{FuENTES Y ANÁLISIS}

Se utiliza como fuente de datos SHARE (Survey of Health, Ageing and Retirement in Europe), un panel de hogares de periodicidad bianual publicado desde 2004-2005 y cuyo último ciclo disponible en el momento de escribir estas líneas, el cuarto, es de 2010-2011. La muestra es representativa para cada país de la población mayor de 50 años no institucionalizada en cada momento de observación y que habla correctamente el idioma oficial de cada país. Además, la encuesta recoge información sobre quien, a partir de su inclusión en la muestra, fue institucionalizado en ciclos posteriores, lo que permite evaluar la importancia de este fenómeno (Laferrère et al. 2013).

En el lanzamiento de SHARE se incluyeron once países cubriendo Escandinavia (Dinamarca y Suecia), Europa central (Austria, Francia, Alemania, Suiza, Bélgica y Holanda) y Europa mediterránea (España, Italia y Grecia). El segundo ciclo, dos años más tarde, conforma como panel a esta operación estadística, pues sigue a las personas que habían sido seleccionadas en la muestra del ciclo anterior, refrescándose la muestra con personas nacidas en 1955 y 1956, que habían cumplido 50 años entretanto. La tercera oleada, denominada SHARELIFE, 
suma al panel una dimensión retrospectiva, pues añade las historias de vida de la población entrevistada: entre otros aspectos, se pregunta por las parejas e hijos que han convivido con el individuo entrevistado, los lugares de residencia y las historias laborales. De momento tenemos a nuestra disposición hasta el cuarto ciclo, que nos enfrenta a las repercusiones producidas por la crisis económica que padecemos.

La utilización de la encuesta propiamente como panel, siguiendo las modificaciones que se producen entre un ciclo y el siguiente, choca con el problema de la "attrition» o desaparición de parte de la muestra a medida que se suma nuevos ciclos. Al evaluar este problema en esta investigación hemos comprobado que solo un $13 \%$ de los casos seleccionados son seguidos en los cuatro ciclos, y que la situación más común es la de haber sido entrevistado solo en el último ciclo, tal y como ocurre para un 36 $\%$ de los individuos. Para evitar una considerable merma de la base de datos hemos decidido el análisis transversal, aunque siempre respetando la estructura de panel de la encuesta (en que un individuo puede ser observado en repetidas ocasiones), con una metodología específica para el análisis de encuestas panel contrastada estadística y empíricamente (Rabe-Hesketh y Skrondal 2008).
En definitiva, la estructura de SHARE es jerárquica con cuatro niveles: país, hogar, individuo y observación. En el procedimiento de recogida de datos, una vez seleccionada la muestra representativa de los individuos mayores de 50 años residentes en un país determinado, se pasa a entrevistarlos, así como también a sus parejas en el momento de observación y a todas las personas mayores de 50 años que conviven en su mismo hogar (véase Klevmarken et al. 2005).

En este estudio se analizan los diez países que han completado el panel en toda su longitud (cuatro ciclos), por lo que se excluye a Grecia, que interrumpió su participación en la cuarta ola, seleccionándose en primer lugar a todas las personas entre 66 y 95 años y, en segundo lugar, a una persona por hogar, con lo que este nivel no estará presente en el análisis.

La Tabla 1 expone el número de individuos seleccionados en las cuatro estructuras de hogar inicialmente posibles: 1) residiendo en una institución, 2) conviviendo en pareja, 3) en hogar privado unipersonal y 4) en compañía de personas fuera de la pareja. El total excede del $100 \%$, pues un individuo puede estar en más de una situación durante el período de observación, al tratarse de cuatro ciclos. Por el contrario, a nivel de observación los valores suman exactamente el

Tabla 1.

Individuos entre 65 y 95 años y observaciones en cuatro posibles situaciones de convivencia según país de residencia

\begin{tabular}{|c|c|c|c|c|c|c|c|c|}
\hline \multirow[b]{3}{*}{ Austria } & \multicolumn{4}{|c|}{ Institucionalizados } & \multicolumn{4}{|c|}{ Conviven en pareja (en hogares privados) } \\
\hline & \multicolumn{2}{|c|}{ Individuos (\%) } & \multicolumn{2}{|c|}{ Observaciones (\%) } & \multicolumn{2}{|c|}{ Individuos (\%) } & \multicolumn{2}{|c|}{ Observaciones (\%) } \\
\hline & 53 & $(2,14)$ & 56 & $(1,62)$ & 1047 & $(42,37)$ & 1443 & $(41,74)$ \\
\hline Alemania & 31 & $(1,97)$ & 42 & $(1,44)$ & 910 & $(57,70)$ & 1819 & $(62,25)$ \\
\hline Suecia & 57 & $(3,10)$ & 64 & $(1,80)$ & 955 & $(51,90)$ & 1977 & $(55,46)$ \\
\hline Holanda & 53 & $(3,41)$ & 66 & $(2,19)$ & 850 & $(54,70)$ & 1702 & $(56,53)$ \\
\hline España & 22 & $(1,11)$ & 29 & $(0,81)$ & 1069 & $(53,72)$ & 2072 & $(58,20)$ \\
\hline Italia & 5 & $(0,25)$ & 5 & $(0,13)$ & 1150 & $(58,26)$ & 2356 & $(61,71)$ \\
\hline Francia & 45 & $(1,62)$ & 63 & $(1,31)$ & 1218 & $(43,81)$ & 2153 & $(44,94)$ \\
\hline Dinamarca & 60 & $(4,70)$ & 84 & $(3,16)$ & 535 & $(41,93)$ & 1184 & $(44,48)$ \\
\hline Suiza & 30 & $(1,95)$ & 32 & $(1,31)$ & 848 & $(55,14)$ & 1310 & $(53,62)$ \\
\hline \multirow[t]{3}{*}{ Bélgica } & 96 & $(3,99)$ & 111 & $(2,34)$ & 1136 & $(47,18)$ & 2357 & $(49,79)$ \\
\hline & \multicolumn{4}{|c|}{ No conviven en pareja (en hogares privados) En hogar unipersonal } & \multicolumn{4}{|c|}{ En compañía } \\
\hline & \multicolumn{2}{|c|}{ Individuos (\%) } & \multicolumn{2}{|c|}{ Observaciones (\%) } & \multicolumn{2}{|c|}{ Individuos (\%) } & \multicolumn{2}{|c|}{ Observaciones (\%) } \\
\hline Austria & 1185 & $(47,96)$ & 1702 & $(49,23)$ & 186 & $(7,53)$ & 256 & $(7,41)$ \\
\hline Alemania & 558 & $(35,38)$ & 951 & $(32,55)$ & 78 & $(4,95)$ & 110 & $(3,76)$ \\
\hline Suecia & 719 & $(39,08)$ & 1402 & $(39,33)$ & 109 & $(5,92)$ & 122 & $(3,42)$ \\
\hline Holanda & 602 & $(38,74)$ & 1173 & $(38,96)$ & 49 & $(3,15)$ & 70 & $(2,32)$ \\
\hline España & 519 & $(26,08)$ & 839 & $(23,57)$ & 380 & $(19,10)$ & 620 & $(17,42)$ \\
\hline Italia & 548 & $(27,76)$ & 987 & $(25,85)$ & 271 & $(13,73)$ & 470 & $(12,31)$ \\
\hline Francia & 1309 & $(47,09)$ & 2278 & $(47,55)$ & 208 & $(7,48)$ & 297 & $(6,20)$ \\
\hline Dinamarca & 604 & $(47,34)$ & 1300 & $(48,84)$ & 77 & $(6,03)$ & 94 & $(3,53)$ \\
\hline Suiza & 595 & $(38,69)$ & 1019 & $(41,71)$ & 65 & $(4,23)$ & 82 & $(3,36)$ \\
\hline Bélgica & 1013 & $(42,07)$ & 2007 & $(42,40)$ & 163 & $(6,77)$ & 259 & $(5,47)$ \\
\hline
\end{tabular}

Fuente: Elaboración a partir de SHARE, ciclos 2004/5, 2006/7, 2008/9, 2010/1. 
Tabla 2.

Individuos y observaciones componentes de la muestra según país de residencia y sexo, población de 65-95 años en hogares privados que no convive en pareja

\begin{tabular}{lcccc|cccc}
\hline & Hombres & $\%$ & Observaciones & $\%$ & Mujeres & $\%$ & Observaciones & $\%$ \\
\hline Austria & 297 & 12,35 & 408 & 9,90 & 102 & 16,1 & 1550 & 13,01 \\
Alemania & 171 & 7,11 & 269 & 6,53 & 440 & 6,94 & 792 & 6,65 \\
Suecia & 261 & 10,85 & 491 & 11,9 & 498 & 7,86 & 103 & 8,67 \\
Holanda & 177 & 7,36 & 334 & 8,1 & 455 & 7,18 & 909 & 7,63 \\
España & 199 & 8,27 & 319 & 7,74 & 614 & 9,69 & 114 & 9,57 \\
Italia & 211 & 8,77 & 365 & 8,86 & 554 & 8,74 & 1092 & 9,16 \\
Francia & 364 & 15,14 & 606 & 14,7 & 108 & 17,1 & 1969 & 16,52 \\
Dinamarca & 197 & 8,19 & 410 & 9,95 & 432 & 6,82 & 984 & 8,26 \\
Suiza & 188 & 7,82 & 302 & 7,33 & 448 & 7,07 & 799 & 6,70 \\
Bélgica & 340 & 14,14 & 616 & 14,9 & 783 & 12,3 & 165 & 13,84 \\
& & & & & & & 100,0 & 1191 \\
Total
\end{tabular}

Fuente: Elaboración a partir de SHARE, ciclos 2004/5, 2006/7, 2008/9, 2010/1.

$100 \%$, pues en cada ciclo una persona solo puede encontrarse en una de las situaciones registradas. En todos los países sin excepción, en ausencia de pareja lo más habitual es vivir solo. Incluso en aquellos países con menores porcentajes de población viviendo sola, España e Italia, esta proporción es notablemente superior a la de aquellos que conviven con una compañía que no es específicamente la pareja. Por ejemplo, en este último país las proporciones de población mayor de 65 años en hogar unipersonal doblan las de quien vive con otras personas. Con todo, hay que recordar que, según la bibliografía, en algunos países la opción de vivir en compañía se sitúa a la par con la de estar institucionalizado (como es el caso de Suecia o Suiza) o incluso esta última situación de residencia es más habitual que vivir con otras personas, como es el caso de Bélgica o, de manera muy destacada, de Dinamarca. La observación con SHARE no señala ningún país en que la institucionalización tenga mayor presencia que vivir en compañía de alguien que no es la pareja, aunque en el caso de Holanda los porcentajes están muy igualados (Tabla 1).

Al seleccionar los individuos que no conviven en pareja y residen en hogares privados, la submuestra final la integran 8742 individuos (un $72,5 \%$ mujeres: un alto desequilibrio entre sexos a causa de la mayor supervivencia de la mujer) observados en 16038 ocasiones (Tabla 2). En definitiva, la información recogida está agrupada en 10 países ( $3^{\text {er }}$ nivel de análisis: país de residencia), de los cuales se han seleccionado una persona de referencia de entre $66 \mathrm{y}$ 95 años por cada hogar ( $2^{\circ}$ nivel de análisis: individuo) durante un máximo de cuatro observaciones temporales (1 ${ }^{\mathrm{er}}$ nivel de análisis: episodio) en que la persona se ha mantenido dentro del rango de edades mencionado. La suma de los porcentajes es del $100 \%$ tanto para los individuos como en los episodios, pues no hay ninguna persona que haya cambiado de país de residencia y haya sido seguida en la encuesta. Finalmente, la inclusión de las variables sobre ingresos económicos y limitaciones para las actividades de la vida diaria ha requerido prescindir de la tercera oleada y reducir la submuestra, ya que el SHARELIFE no recoge dicha información.

Complementariamente, y a partir del segundo ciclo, podemos descubrir en algunas situaciones de qué situación residencial se partía. No siempre, pues no en todos los casos se ha podido seguir a la persona a lo largo de todo el período de observación, dándose muchas pérdidas y otras tantas incorporaciones a la muestra, tal y como ya hemos comentado. Esto nos imposibilita el análisis longitudinal, obligándonos a un análisis transversal, en que un individuo que no convive en pareja o bien reside en un hogar unipersonal, o bien en uno privado multipersonal o en una institución (este último a partir del segundo ciclo). En esta investigación nos centraremos en la primera relación, es decir, en la que se establece entre quienes viven en un hogar unipersonal y quienes residen en uno multipersonal pero sin estar institucionalizados.

En definitiva, a nivel operativo, la variable dependiente recoge la ratio entre la probabilidad de vivir con otras personas o en un hogar unipersonal, que denominaremos como «relación de acompañamiento» (RA). Esta variable dependiente es dicotómica, por lo que la técnica apropiada es la regresión logística. Aunque tratemos con información transversal (pues en cada ciclo la encuesta es representativa para la población mayor de 50 años), las muestras no son independientes entre sí, pues en un panel los mismos individuos son entrevistados en repetidas ocasiones, y solo hay nuevas incorporaciones para conservar la representatividad transversal a pesar de las pérdidas de la muestra original. Ello precisa de la utilización de la regresión logística específica para datos panel (Rabe-Hesketh y Skondal, 2008). 
En el capítulo de resultados presentamos el proceso de construcción del modelo final paso a paso (añadiendo progresivamente las variables incluidas en el modelo general), pues de esta manera nos permite testar las hipótesis y discernir entre los factores que deben o no ser incluidos en el modelo general, explicando por qué forman parte de la explicación o han sido desechados. En definitiva, el análisis paso a paso permite comprobar hasta qué punto la introducción de una nueva variable supone un cambio en los efectos de las hasta el momento introducidas. Por ejemplo, si no es la edad la variable importante sino el número de dificultades en la vida diaria lo que hace que alguien conviva con otras personas en vez de solo, una vez introducida esta segunda variable dejará de ser significativo el efecto del anterior.

Se relaciona la RA con una serie de variables independientes, una vez se ha controlado por edad, sexo, país de residencia y ciclo de observación. Estas variables independientes son el nivel educativo, el número de hijos, el nivel de ingresos y las limitaciones para las actividades de la vida diaria. A cada paso se incluye una de las variables, comprobando posibles interacciones con otras de las variables incluidas en el modelo, conservando aquellas que son significativas y replanteando el efecto de las variables en el modelo y las posibles modificaciones que se constaten.

El currículum educativo varía en función del país observado. La «International Standard Classification of Education (ISCED)» es el instrumento más eficaz para comparar el nivel de instrucción entre países. En SHARE cada país clasifica la educación en función de su propio currículum y, una vez recogidos los datos, se estandarizan a posteriori según las categorías de ISCED97. La adaptación de esta clasificación a los diez países aquí considerados obliga a reducir las categorías a tres: 1) máximo educación básica u obligatoria, 2) educación media y 3) educación universitaria. Queremos destacar, por último, que esta variable no cambia con el tiempo, es decir, permanece a nivel de individuo a lo largo de toda la biografía registrada del mismo, no de la observación en un ciclo determinado (ello es así porque estamos tratando con población mayor de 65 años, y a estas edades el aumento en el nivel de instrucción es inapreciable).

La encuesta recoge información sobre la realización de diversas actividades de la vida diaria en variables dicotómicas que codifican con ' 1 ' si el entrevistado declara dificultad para llevarlas a cabo (y ' 0 ' en caso contrario). Siguiendo los indicadores clásicos de la literatura se han agrupado aquí en dos categorías, las actividades básicas de la vida diaria (ABVD) y las actividades instrumentales en la vida diaria (AIVD), que acumulan en sendas variables el número de actividades para las que el entrevistado declara dificultad para su realización. Las ABVD se refieren al autocuidado, en este caso a: comer, vestirse, levantarse y acostarse en la cama, caminar, bañarse e ir al baño; y las AIVD suponen la interacción con el entorno e incluyen: llamar por teléfono, hacer la compra, coger transportes públicos, preparar comidas, tomar sus medicinas, administrar dinero y hacer tareas del hogar.

Para dar cuenta del nivel económico individual se ha calculado una variable a partir de los ingresos económicos individuales, que la encuesta recoge desagregados por tipo de entrada. Se han sumado todos los ingresos y se ha calculado el cuartil de pertenencia dentro de cada país y período para toda la población entrevistada de 65 a 95 años. El nivel de ingresos suele ser una variable con un elevado porcentaje de casos sin información (que en concreto oscila en la SHARE entre el 15 y el $30 \%$ según país), lo que supone una pérdida importante de casos, de manera que se ha optado por incluir en el modelo la categoría de «sin información».

\section{Resultados}

\section{Evolución de las variables de control: país de residen- cia, edad, sexo y período de observación}

A continuación presentamos un modelo en que la RA está en función de una serie de variables explicativas que se irán introduciendo progresivamente. En el análisis con datos de panel no se pueden traducir directamente los coeficientes obtenidos a proporciones o probabilidades, sino que sirven solo para describir los cambios acaecidos (Rabe-Hesketh y Skrondal 2008). Por ello se han estimado las proporciones observadas a partir del análisis de un solo ciclo de SHARE (Tabla 3). Para empezar, describiremos el efecto de las variables estructurales de control y su evolución en el tiempo.

Al iniciar la construcción de este modelo presentamos únicamente la descripción de los patrones según país de residencia (Tabla 3). La división espacial recogida en la bibliografía aparece con claridad. Así, se presenta un conjunto de países que destacan porque la población mayor reside en mayor medida en hogares de solitarios: son, de mayor a menor soledad, Holanda (con un nivel de compañía claramente distante del resto de países observados, pues no llega a un 5,5\% y donde, de acuerdo a la bibliografía y la observación con SHARE, la institucionalización alcanza proporciones más elevadas), el conjunto formado por Dinamarca y Suiza y, en menor medida, Suecia (todos ellos con un porcentaje de entre el 6,5 y el $8 \%$ ). Un segundo grupo une a Europa Central: Alemania, Bélgica, Francia y Austria (sin una diferencia estadísticamente significativa entre ellos: con una proporción de alrededor de un $11 \%$ ). Finalmente, el conjunto formado por Italia y España, representantes de la Europa mediterránea, presentan una probabilidad de vivir en compañía significativamente mayor 
que en sus países europeos vecinos; de hecho, sus porcentajes estimados de quienes viven acompañados entre quienes no conviven en pareja son: tres veces superiores a los anteriores para Italia, y cuatro veces en el caso de España.

Debemos recordar que los países en que vivir acompañado es una opción menos extendida coinciden con aquellos de mayor población institucionalizada y viceversa: la institucionalización es residual precisamente en España y, muy especialmente, en Italia, los dos países en que residir acompañado está más extendido.

Tabla 3.

Relación de acompañamiento según país (coeficientes y porcentaje estimado).

\begin{tabular}{lccc}
\hline & Coeficiente & Significación & \% estimada \\
\hline Holanda & $-1,58$ & $* * *$ & 5,45 \\
Dinamarca & $-0,98$ & $* * *$ & 6,60 \\
Suiza & $-0,96$ & $* * *$ & 6,83 \\
Suecia & $-0,53$ & $* *$ & 7,76 \\
& & & \\
Alemania & $-0,37$ & ns. & 10,44 \\
Bélgica & $-0,15$ & ns. & 10,91 \\
Francia & $-0,12$ & $n s$. & 10,73 \\
Austria & 0,00 & ref. & 11,83 \\
& & & \\
Italia & 2,71 & $* * *$ & 31,35 \\
España & 3,88 & $* * *$ & 41,23 \\
\hline
\end{tabular}

\begin{tabular}{lcc} 
& Coeficiente & Error estándar \\
\hline Innsig2u & 2,63 & 0,05 \\
& & \\
sigma_u & 3,73 & 0,10 \\
rho & 0,81 & 0,01 \\
\hline
\end{tabular}

Fuente: Elaboración a partir de SHARE, 2004/5 a 2010/11.

Nota: Nivel de significación *** $99 \%$, * $95 \%$, * 90 \%, 'ns' no significativo.

Sobre la diferencia regional vamos a añadir la pauta por edad: en general, la probabilidad de vivir acompañado en vez de solo se reduce ligeramente entre los 66 y los 70 años, se estabiliza a partir de entonces y se incrementa con fuerza a partir de los 80 años (Gráfico 1), pues desde esta edad en adelante, a más años, mayor probabilidad de convivir con otras personas en lugar de hacerlo en soledad; en concreto, mientras que esta proporción es del 10 $\%$ a los 80 años, alcanza un $25 \%$ a los 95 años. Hemos comprobado a través del análisis longitudinal que la mayor propensión a vivir solo entre los 66 y los 70 años se da con independencia del tipo de hogar anterior, es decir, no se encuentra relacionada con ningún proceso específico como pudiera ser la emancipación de los hijos en hogares monoparentales: todo pareciera indicar que hasta los 70 años se vive más solo porque así se decide. Por otro lado, lo que ocurre a partir de los 80 años es lo pronosticado: a mayor dependencia por razón de edad, mayor probabilidad de residir con otras personas. Además, también a partir de los 80 años se constata que se incrementa de manera substancial la tasa de institucionalización: en otras palabras, es la edad en que en Europa occidental las personas precisan de ayuda en el hogar en que viven para su quehacer cotidiano.

Esta pauta se puede reducir técnicamente a un modelo con la edad en formato continuo (en lugar de discreto), utilizando dos factores, a saber, la edad simple y la edad cuadrática, tal y como se aprecia en el Gráfico 1 y que se incluirán a partir de ahora en el modelo, por mor de la parsimonia.

Con todo, la RA de los países se mantiene al introducir la edad en el modelo. Es decir, ni los países en que se reside más en soledad son aquellos con mayor proporción de menores de 80 años (los que más viven solos), ni los países en que se reside más en compañía (en ausencia de pareja) coinciden con los de mayor proporción de mayores de 80 años, cuya probabilidad de vivir acompañados se incrementa exponencialmente con la edad. En definitiva, la diferencia geográfica observada no ha sido causada por una estructura por edad diferencial, persistiendo de momento la hipótesis de la cultura específica de los países, pues viven más en soledad los del norte, menos los de centro Europa y mucho menos los del sur, sin que ello se achaque a que unos están más envejecidos que otros.

La pauta de edad confirma la H1, con dos particularidades. La probabilidad de estar acompañado a partir de los 80 años, se da de manera más contundente en Suecia, en comparación con los otros países analizados, mientras que en Alemania la edad no supone diferencias significativas sobre la opción de vivir en un hogar privado multipersonal frente a que el mismo sea unipersonal (Gráfico 2). Este importante incremento de la convivencia a edades avanzadas observado en Suecia podría deberse no solo a que los ancianos vivan más acompañados, sino también al efecto de una mayor propensión a la institucionalización de los mayores cuando tienen dificultades para seguir viviendo solos. Es decir, la salida de observación de la población residente en hogares que vivía sola y que se ha mudado a una residencia podría explicar parcialmente una mayor proporción de corresidencia entre las edades más avanzadas. Para confirmar esta hipótesis se debería acometer un análisis longitudinal que capte estos procesos de institucionalización.

En el siguiente paso nos preguntamos por la evolución temporal de la relación de acompañamiento. No se ha observado diferencia significativa en la probabilidad de vivir acompañado en vez de solo para los tres primeros ciclos 
Gráfico 1.

Relación de acompañamiento según edad (coeficientes de regresión logística con datos panel y porcentaje estimado).

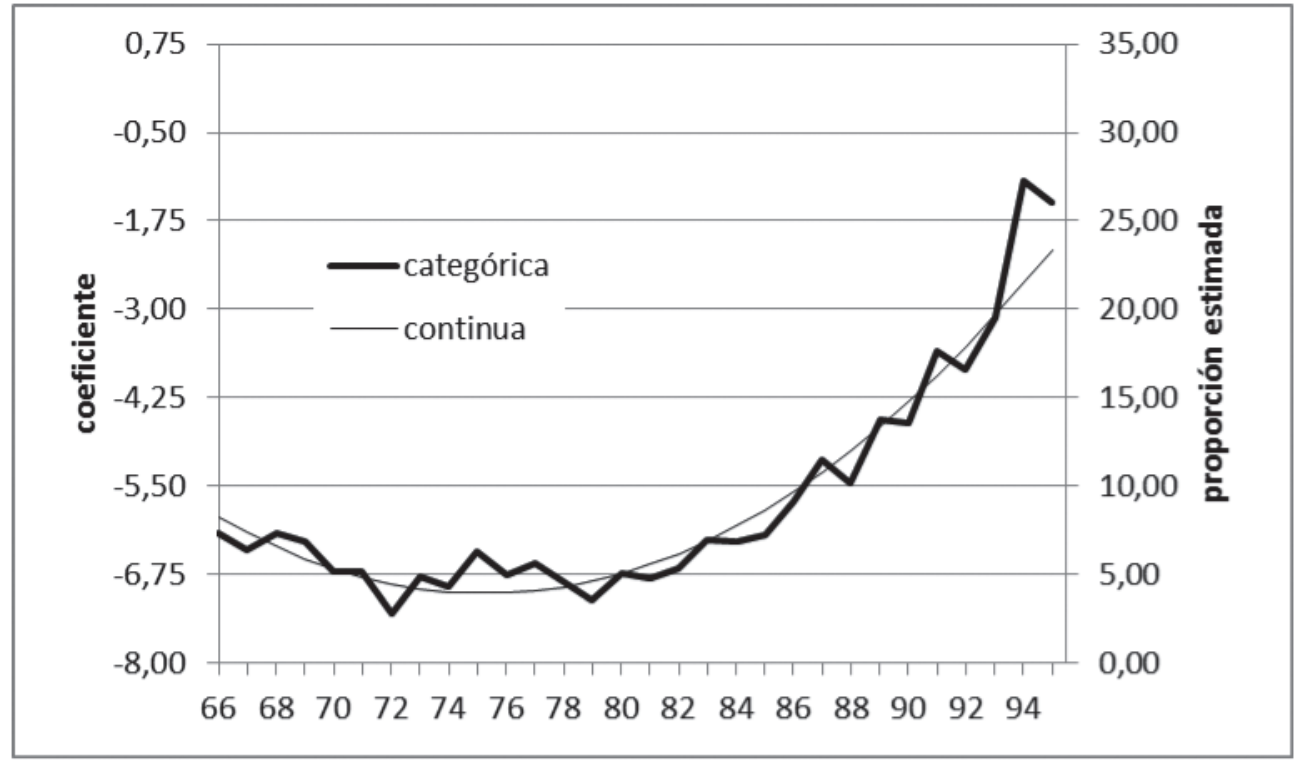

Fuente: Elaboración a partir de SHARE, 2004/5 a 2010/1.

Gráfico 2.

Pauta por edad en la RA. Patrones específicos de Suecia y Alemania (coeficientes).

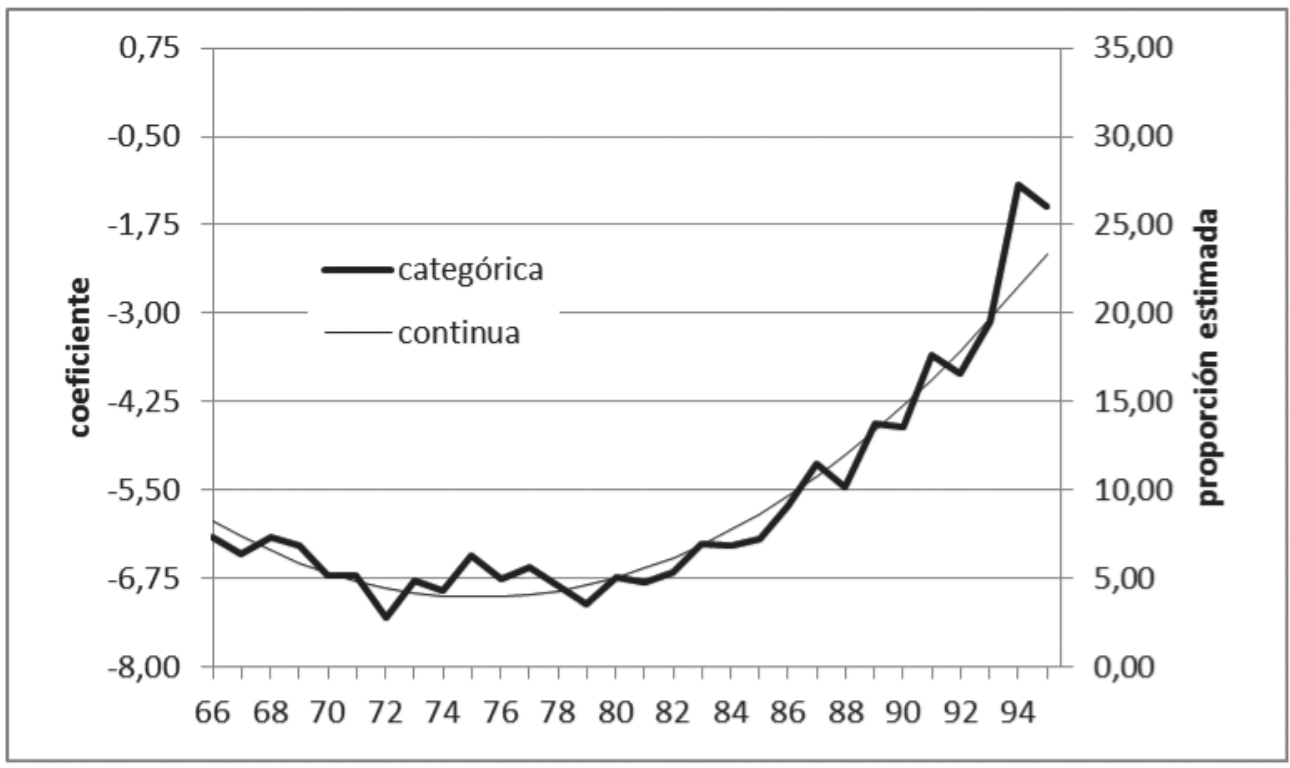

Fuente: Elaboración a partir de SHARE, 2004/5 a 2010/1.

(de 2004/5 a 2008/9), pero a partir del cuarto (2010/11) se ha registrado un substancial incremento de hogares compartidos en detrimento de quienes viven solos. Es decir, de acuerdo con la $\mathrm{H} 2$, la crisis ha provocado que la gente mayor conviva más acompañada y menos sola, sin que lleguemos a establecer a estas alturas de la investigación quién ayuda a quién en el interior del hogar; en otras palabras, no sabemos si la gente mayor convive con otras personas para ayudar a los convivientes o para que estos les ayuden. Cabe añadir, sin embargo, que en futuros avances podremos desvelar el sentido de la ayuda, pues la información se encuentra disponible en SHARE.

Debemos destacar, además, que solo al añadir el efecto del tiempo de observación, el género aparece como una 
variable a tener en cuenta, y ello es debido a que, mientras que hasta el estallido de la crisis las mujeres convivían acompañadas en mucha mayor medida que los hombres, en el último período observado las probabilidades entre géneros se han igualado, e incluso revertido. A ello atiende el factor de interacción entre el género y el cuarto ciclo que se puede apreciar en el modelo expuesto en la Tabla 4, y que se representa en el Gráfico 3. Por otro lado, también hemos comprobado que esta evolución fue similar en toda la Europa visitada en esta investigación, de manera que no se precisa introducir un factor de interacción entre el momento de observación y el país de residencia.

En conclusión, la evolución del fenómeno tuvo forma de J (Gráfico 3), creciendo agudamente con la explosión de la crisis. Hasta ese momento las mujeres siempre habían tenido probabilidades de convivir más elevadas que los varones, pero las mismas se igualaron por sexo en 2010/1 al tener mayor repercusión la crisis en las formas de convivencia de los hombres. Este mayor impacto bien puede deberse a que la población masculina se ha visto más afectada por la crisis que la femenina, o también a que el aumento de hogares compartidos refleja el alcance de la crisis sobre los hijos de la población observada, que en caso de apuros económicos pueden verse forzados a regresar al hogar paterno 0 materno, 0 a acoger a sus mayores en el propio hogar.

Anotar que en el período 2004-2009 las diferencias debidas al momento de observación no son significativas, sin embargo, como muestra el Gráfico 3, los coeficientes son claramente diferentes e indican que la crisis económica ha supuesto en Europa un incremento en la relación de acompañamiento (aunque la falta de muestra permita afirmarlo con suficiente contundencia estadística solo para el cuarto ciclo).
Tabla 4.

Relación de acompañamiento (coeficientes) según país de residencia, edad, sexo y período de observación.

\begin{tabular}{|c|c|c|}
\hline & Coeficiente & Significación \\
\hline Austria & 0,00 & ref. \\
\hline Holanda & $-1,49$ & $\star \star * *$ \\
\hline España & 4,50 & $* * *$ \\
\hline Italia & 3,24 & $* * *$ \\
\hline Francia & $-0,08$ & ns. \\
\hline Dinamarca & $-0,83$ & $\star * *$ \\
\hline Suiza & $-1,01$ & $\star \star *$ \\
\hline Bélgica & $-0,04$ & ns. \\
\hline Edad simple & $-1,60$ & $\star \star \star *$ \\
\hline Edad cuadrática & 0,01 & $* * *$ \\
\hline Suecia (interacción) & 34,38 & ns. \\
\hline edad simple & $-1,06$ & * \\
\hline edad cuadrática & 0,01 & ** \\
\hline Alemania (interacción) & $-51,63$ & * \\
\hline edad simple & 1,40 & $* *$ \\
\hline edad cuadrática & $-0,01$ & $* *$ \\
\hline Hombres en 2004-2009 & 0,00 & ref. \\
\hline Mujeres en 2004-2009 & 0,78 & $* * *$ \\
\hline Hombres en 2010/11 & 1,74 & $* * *$ \\
\hline Mujeres en 2010/11 & 1,57 & $* * *$ \\
\hline \multirow[t]{2}{*}{ Constante } & 54,37 & $* * *$ \\
\hline & Coeficiente & Error estándar \\
\hline /lnsig2u & 2,94 & 0,05 \\
\hline sigma_u & 4,36 & 0,10 \\
\hline rho & 0,85 & 0,01 \\
\hline
\end{tabular}

Fuente: Elaboración a partir de SHARE, 2004/5 a 2010/1.

Nota: La Tabla presenta las interacciones que han resultado significativas, así la pauta de edad diferencial para Suecia y Alemania y el efecto diferencial según género para el cuarto ciclo.

Gráfico 3.

Evolución temporal de la relación de acompañamiento (coeficientes) según sexo.

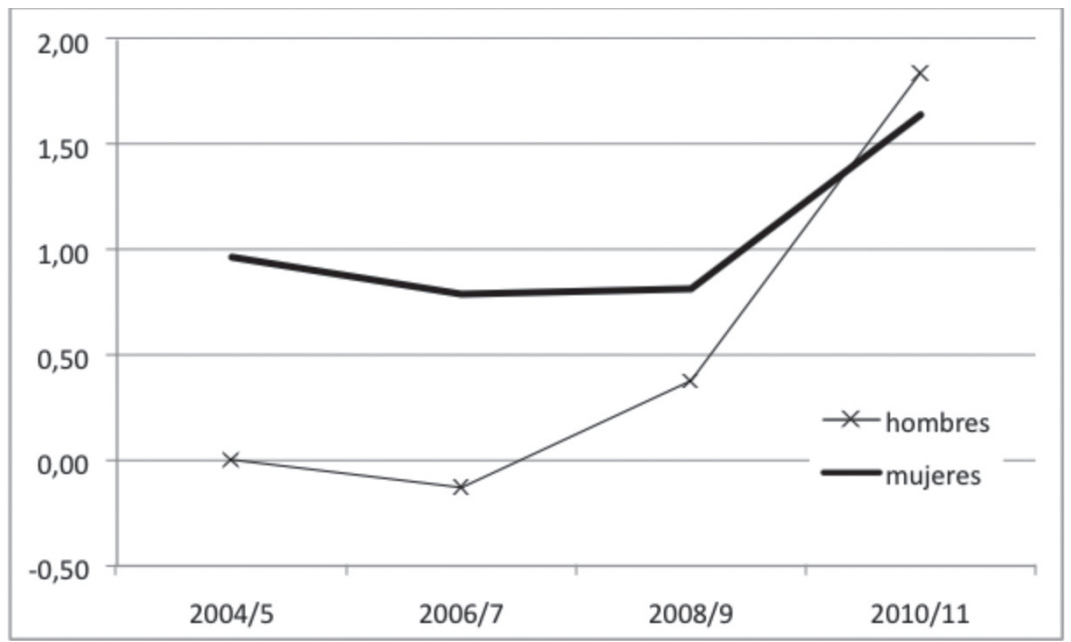

Fuente: Tabla 4. 
Tabla 5.

Efecto del nivel de instrucción en la relación de acompañamiento (coeficientes).

\begin{tabular}{lcc}
\hline & Coeficiente & Significación \\
\hline Máximo educación básica & 0,00 & ref. \\
\hline Educación media & $-1,12$ & ${ }^{* * *}$ \\
(en Suiza) & 0,56 & ${ }^{* * *}$ \\
\hline Educación universitaria & $-1,71$ & ${ }^{* * *}$ \\
\hline
\end{tabular}

Fuente: Elaboración a partir de SHARE, 2004/5 a 2010/11.

Nota 1: Los coeficientes mostrados en las interacciones resultan de la suma de los coeficientes de las variables involucradas en la misma.

Nota 2: Controlando por país, edad, sexo y momento de observación.

El efecto del nivel de instrucción, número de hijos y renta relativa sobre el tipo de hogar

Una vez controlado por la estructura demográfica y el momento de observación, este modelo incluye el nivel de instrucción, asumiendo -siguiendo la teoría del capital humano- que a mayor grado educativo, mayor renta y, en consecuencia, mayor independencia en la elección del tipo de hogar. En general, confirmando parcialmente la H3, el convivir con otras personas (que no sean la pareja) en lugar de vivir solo es tanto menos probable cuanto mayor es el nivel de instrucción, sin que existan diferencias en este sentido entre hombres y mujeres. En concreto, tal y como podemos apreciar por los coeficientes expuestos en la Tabla 5, la relación de acompañamiento es 1,12 veces menor con la educación media que con la básica, y 1,71 veces menor en la universitaria en relación a la misma referencia. Salvo en Suiza, donde se ha comprobado que no siguen este patrón quienes habian accedido a una educación media (coeficiente de 0,56 ).
¿A mayor número de hijos mayor probabilidad de convivir?

Al introducir el número de hijos como variable explicativa, el específico patrón sueco desaparece: la pauta por edad observada en Suecia era debida a la presencia diferencial de hijos, pues una vez controlábamos por esta variable la pauta por edad para este país se asemeja a la observada en la referencia.

La H4 de esta investigación proponía que a mayor número de hijos, mayor probabilidad de residir no en soledad sino en compañía, siempre -recordemos- en ausencia de pareja. Controlando por todas las variables independientes que hasta ahora hemos considerado (país de residencia, edad, sexo, año de observación y nivel de instrucción), la máxima enunciada se cumple: a mayor número de hijos, mayor probabilidad de convivir con otras personas en vez de hacerlo solo (Gráfico 4). Hay que anotar, sin embargo, que esta regla se rompía en la relación entre uno y dos hijos, pues la ratio de convivencia era algo superior si se había tenido solo un hijo que si se había tenido un par. Es decir, todo indica que tener un solo hijo supone en mayor medida la presencia de este en el hogar que tener dos. Añadir que, con la eclosión de la crisis (2010-11), la relación de acompañamiento de la población mayor que no ha tenido hijos se redujo significativamente.

Para simplificar el modelo se incorpora la variable relativa al número de hijos agrupando a quien tiene cinco o más. Al añadir esta variable, además de la interacción entre residir en Suecia y la edad, también la particularidad descubierta para el género durante el cuarto ciclo queda anulada por falta de significatividad. En definitiva, una vez se controla por el número de hijos, ni Suecia se presenta con una pauta por edad distinta a los demás

Gráfico 4.

Relación de acompañamiento según número de hijos y período de observación.

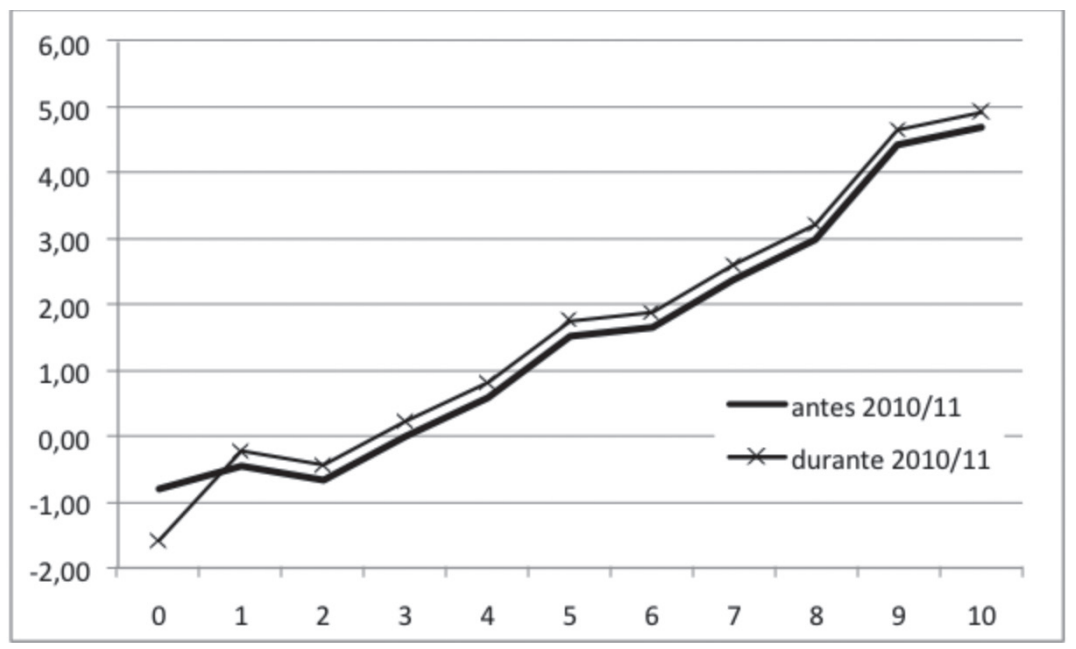

Fuente: Elaboración a partir de SHARE, 2004/5 a 2010/1.

Nota: Controlando por país, edad, momento de observación, sexo y nivel de instrucción. 
países, ni el género aparece distinto durante el cuarto ciclo, sino que reviste importancia a lo largo de todo el período observado, pues las mujeres que no conviven en pareja siempre han experimentado una probabilidad de vivir con otras personas en vez de solas substancialmente superior a la de los hombres en la misma situación. Además, tampoco el momento de observación (antes 0 después del estallido de la crisis) aparece con suficiente intensidad, a no ser a través de su interacción con quien no ha tenido hijos (Tabla 6). Esto refuerza la interpretación que el aumento de hogares compartidos entre los mayores durante la expansión de la crisis responde también al empeoramiento de la situación de los hijos. La convivencia se revela como una estrategia de solidaridad intergeneracional que opera en ambas direcciones.

De nuevo nos vemos obligados a anotar que aunque hayamos perdido significación estadística, ello no significa que la evolución temporal no continúe siendo importante, es especial para los varones, tal y como comprobamos en el Gráfico 5: por ejemplo, cuando observamos a quienes tenían dos hijos, percibimos un salto cualitativo con la crisis económica para los varones, a pesar de que la escasez de muestra no nos dote de suficiente significación estadística. En definitiva, la segunda hipótesis formulada continúa siendo correcta (cuanto menos para los varones), aunque el número de hijos la enmascare en gran medida.

Al llegar a este paso en la construcción del modelo aparece otra ventaja, pues los coeficientes entre los países se presentan ahora con la suficiente significación para distinguirlos con claridad de la referencia (Austria), con la única excepción de Alemania, característica que nos acompañará hasta el final de esta investigación. En conclusión, podemos afirmar que los patrones observados entre países
Tabla 6.

Relación de acompañamiento (coeficientes) en función del país de residencia, edad, género, educación, número de hijos y momento de observación.

\begin{tabular}{|c|c|c|}
\hline & Coeficiente & Significación \\
\hline Austria & 0,00 & ref. \\
\hline Suecia & $-2,62$ & *** \\
\hline Holanda & $-2,77$ & *** \\
\hline España & 4,50 & *** \\
\hline Italia & 3,00 & *** \\
\hline Francia & $-0,63$ & ** \\
\hline Dinamarca & $-3,80$ & *** \\
\hline Suiza & $-1,94$ & *** \\
\hline Bélgica & $-0,53$ & * \\
\hline Edad simple & $-1,57$ & $x^{* * *}$ \\
\hline Edad cuadrática & 0,01 & *** \\
\hline Alemania (interacción) & $-53,04$ & * \\
\hline edad simple & 1,42 & * \\
\hline edad cuadrática & $-0,01$ & * \\
\hline Mujeres & 0,42 & ** \\
\hline Educación media & $-0,95$ & $* * \star$ \\
\hline (en Suiza) & 0,79 & *** \\
\hline Educación universitaria & $-1,59$ & *** \\
\hline Sin hijos & $-0,80$ & 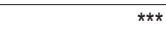 \\
\hline 1 hijo & $-0,45$ & * \\
\hline 2 hijos & $-0,66$ & $* * *$ \\
\hline 3 hijos & 0,00 & ref. \\
\hline 4 hijos & 0,60 & ** \\
\hline 5 o más hijos & 2,01 & $* * *$ \\
\hline ciclo 2010/11 & 0,22 & * \\
\hline (sin hijos en 2010/11) & $-0,78$ & *** \\
\hline \multirow[t]{2}{*}{ Constante } & 54,49 & *** \\
\hline & Coeficiente & Error estándar \\
\hline /Insig2u & 3,21 & 0,05 \\
\hline sigma_u & 4,98 & 0,11 \\
\hline rho & 0,88 & 0,00 \\
\hline
\end{tabular}

Fuente: Elaboración a partir de SHARE, 2004/5 a 2010/1.

Gráfico 5.

Evolución temporal de la relación de acompañamiento.

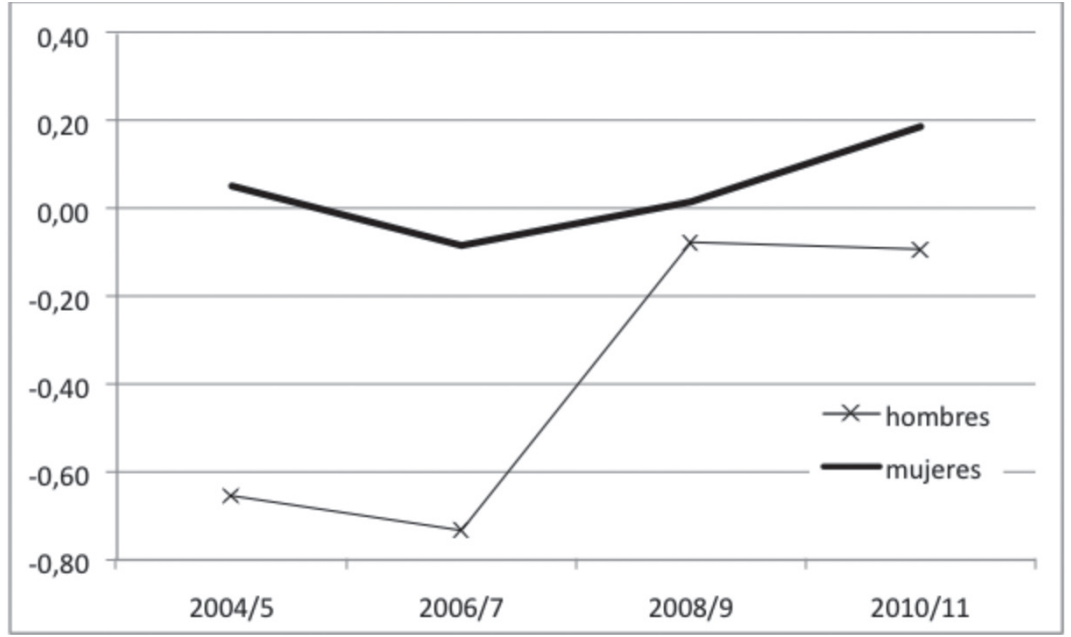

Nota 1: Controlando por país, edad, momento de observación y nivel de instrucción.

Nota 2: Los coeficientes son para quienes tienen 2 hijos. 
tampoco deben su razón de ser a una fecundidad diferencial entre ellos, sino que la causa debe achacarse a una cultura idiosincrática en las distintas áreas, pues ni ahora ni en lo que queda de análisis ninguna variable conseguirá erosionar esta distancia interregional.

Destacar finalmente que el nivel de instrucción, con la particularidad de que reviste un efecto contrario para la población con estudios medios en Suiza, mantiene inmutable su posición al incluir como variable los hijos habidos.

\section{Limitaciones en las actividades de la vida diaria}

Las dos variables que a continuación se aplican no se recogieron para el tercer ciclo (SHARELIFE), por lo que todas las particularidades del mismo quedaran escondidas. Así sucede con la siguiente variable que incluimos en el modelo explicativo: las limitaciones en las actividades de la vida diaria. Tal y como se ha expuesto en la metodología, SHARE ofrece un conjunto de limitaciones básicas (ABVD) y otras instrumentales (AIVD). Hemos comprobado que ambas dimensiones del quehacer cotidiano están relacionadas, y que las limitaciones en las AIVD anulan la intensidad de las ABVD. Nos parece destacable el hecho de que sean las limitaciones para las actividades instrumentales, que suponen la interacción con el entorno, las que tienen más fuerza explicativa que las actividades básicas, de autocuidado, que requieren de la presencia de un cuidador y presumiblemente están más asociadas a patrones de corresidencia. Esto indica que las limitaciones para realizar las actividades instrumentales ya vulneran la independencia residencial de las personas.

La escala de limitaciones instrumentales se ha agrupado en cuatro niveles significativos, según si un individuo no tenía ninguna (categoría de referencia), tenía de 1 a 3 dificultades, 4 limitaciones, o 5 o más dificultades instrumentales. Esta variable resulta ser muy importante, en especial si la persona tenía 5 o más limitaciones, característica que fuerza sobremanera la necesidad de convivir con otras personas y no en soledad.

Tal y como se esperaba, y confirmando la $\mathrm{H} 1$, la pérdida de autonomía personal, en particular las limitaciones para las AIVD, aumenta sustancialmente la probabilidad de convivir con otras personas. Controlando por todas las variables consideradas hasta el momento y considerando como referencia el no tener ninguna dificultad instrumental para la vida diaria (con un coeficiente de 0,00 ), se comprueba que este indicador se incrementa en 0,6 para quien tiene entre 1 y 3 limitaciones instrumentales, se duplica respecto al anterior para quien tiene 4 y es tres veces superior a la referencia para quien experimenta 50 más de estas limitaciones (Tabla 7).

Al introducir esta nueva variable su efecto anula el del género: no se trata tanto de si alguien es hombre o mujer, sino fundamentalmente de su estado funcional y de limitaciones para la vida diaria que padece. Asimismo el aumento de corresidencia observado en el período de crisis económica se desvanece en cuanto se incluyen las variables del número de hijos y de las limitaciones funcionales. Una posible explicación, que requeriría de comprobación, sería que, debido a la crisis y el aumento de desempleo, los hijos tienen una mayor disponibilidad y/o necesidad para atender a sus progenitores en caso de pérdida de autonomía funcional, favoreciendo el aumento de corresidencia entre unos y otros.

Además, al introducir las dificultades instrumentales para la vida diaria como variable explicativa, la pauta por edad se agudiza hasta los 85 y se suaviza más adelante (Gráfico 6),

Gráfico 6.

Pauta por edad de la relación de acompañamiento según AIVD.

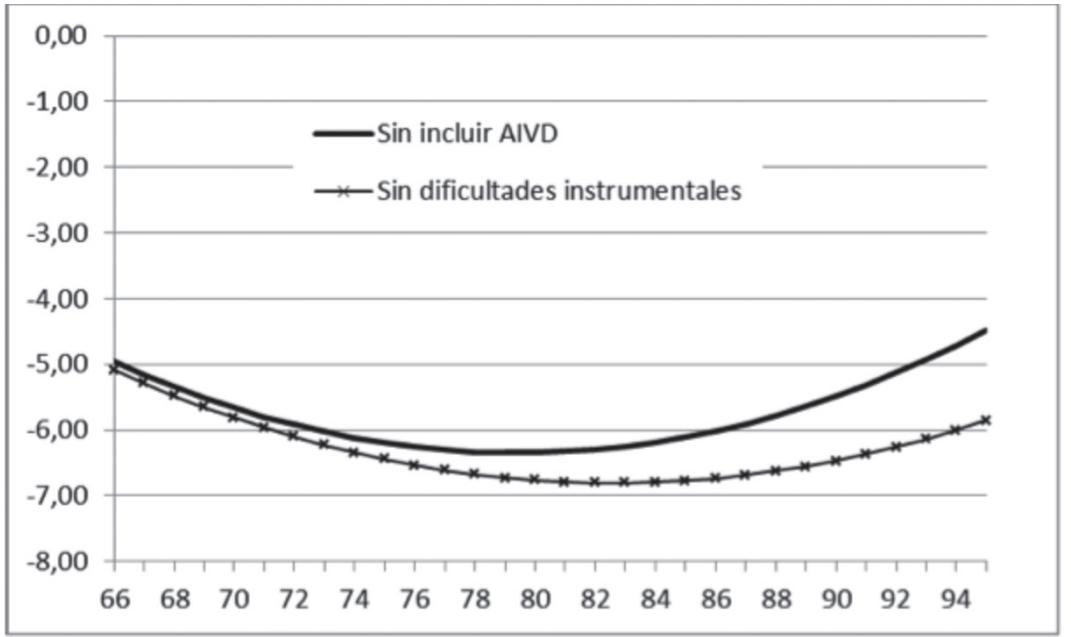

Fuente: Elaboración a partir de SHARE, 2004/5, 2006/7 y 2010/1. 
lo que cabe interpretar como que no es tanto la edad lo que incide sobre la relación de acompañamiento sino la pérdida de funcionalidad. En otras palabras, en ausencia de dificultades funcionales, entre los 65 y los 85 años, a mayor edad, mayor preferencia a vivir solo; y únicamente a partir de los 90 años de edad, la edad está directamente en relación con la relación de acompañamiento. En definitiva, debemos retocar la primera hipótesis: en general, a mayor edad, mayor residencia en hogares unipersonales en lugar de pluripersonales, a no ser que las dificultades funcionales lo hagan inviable.

Tabla 7.

Relación de acompañamiento según país de residencia, edad, nivel de instrucción y número de hijos y momento de observación.

\begin{tabular}{|c|c|c|}
\hline & Coeficiente & Significación \\
\hline Austria & 0,00 & ref. \\
\hline Suecia & $-2,77$ & $* * *$ \\
\hline Holanda & $-2,74$ & $* * *$ \\
\hline España & 3,99 & $* * *$ \\
\hline Italia & 2,75 & $* * *$ \\
\hline Francia & $-0,58$ & $* *$ \\
\hline Dinamarca & $-3,53$ & $* * *$ \\
\hline Suiza & $-1,79$ & $* * *$ \\
\hline Bélgica & $-0,56$ & * \\
\hline Edad simple & $-1,03$ & $* * *$ \\
\hline Edad cuadrática & 0,01 & $* * *$ \\
\hline Alemania (interacción) & $-71,13$ & ** \\
\hline edad simple & 1,87 & ** \\
\hline edad cuadrática & $-0,01$ & $* *$ \\
\hline Educación media & $-1,06$ & $* \star *$ \\
\hline (en Suiza) & 1,72 & ** \\
\hline Educación universitaria & $-1,40$ & $* \star *$ \\
\hline Sin hijos & $-1,21$ & $* * *$ \\
\hline (sin hijos en 2010/11) & $-0,48$ & * \\
\hline 1 hijo & $-0,33$ & ns. \\
\hline 2 hijos & $-0,51$ & ** \\
\hline 3 hijos & 0,00 & ref. \\
\hline 4 hijos & 0,66 & $* *$ \\
\hline 5 o más hijos & 1,93 & $* * *$ \\
\hline Ninguna dificultad & 0,00 & ref. \\
\hline entre 1 y 3 & 0,63 & $* * *$ \\
\hline 4 & 1,40 & $* * *$ \\
\hline 50 más dificultades & 2,65 & $* \star *$ \\
\hline \multirow[t]{2}{*}{ Constante } & 36,55 & $* * *$ \\
\hline & Coeficiente & Error estándar \\
\hline /Insig2u & 2,94 & 0,06 \\
\hline sigma_u & 4,35 & 0,12 \\
\hline rho & 0,85 & 0,01 \\
\hline
\end{tabular}

Fuente: Elaboración a partir de SHARE, 2004/5, 2006/7 y 2010/1.
¿A mayor renta, mayor soledad?

Otra hipótesis pronunciada al inicio de este trabajo reza que alguien vive solo si puede permitírselo, pues no precisa convivir con alguien para obtener ayuda, ya que puede adquirir los servicios que necesite en el mercado. Esta variable clave también está incluida en nuestra base de datos: esperamos que cuanto mayor sea el nivel de renta, menor la corresidencia y mayor la vida en solitario. Pero por mucho que hemos intentado que esta variable constituyera un factor explicativo en nuestro modelo de la relación de acompañamiento, ello no ha sido posible: la renta relativa de un individuo en relación a su país de residencia y momento de observación no ayuda a explicar por qué las relaciones de acompañamiento son diferentes en unos países que en otros, o en distintos grupos sociales. Así, la H3 queda solo parcialmente confirmada por el efecto negativo del nivel educativo sobre la relación de acompañamiento.

\section{CONCLUSIONES Y DISCUSIÓN}

Retomando la pregunta inicial, ¿las diferencias interregionales en las formas de convivencia de los mayores se deben a factores estructurales o coyunturales, o bien a elementos culturales? De entrada todo hace pensar que los patrones residenciales específicos de cada país se deben a culturas idiosincráticas. La ratio observada de quienes conviven en compañía de personas fuera de su pareja y quienes viven en soledad no presenta diferencias estadísticamente significativas a lo largo de la Europa central, representada por Austria, Alemania, Francia y Bélgica, un área con un estado de bienestar conservador que muestra un punto medio en el ranquin de nuestro objeto de estudio. Frente a ella, la Europa nórdica y socialdemócrata, donde es relativamente mucho más probable vivir en soledad más allá de los 65 años, formada por el conjunto de Suecia, Holanda, Dinamarca y también Suiza (como único elemento de la Europa central y con estado de bienestar conservador). Suecia encabeza los países con más solitarios entre los 65 y los 80 años, pero a partir de esta edad, las proporciones de población que convive acompañada se alzan con fuerza frente a la de los que viven en solitario, lo que se explica por un patrón de fecundidad diferenciado -en línea con los resultados de lacovou (2000)- y posiblemente también debido a que muchos de los que viven solos salen de observación al institucionalizarse cuando sufren un importante deterioro del estado de salud (Laferrère et al. 2013). En el otro extremo, con un mayor acompañamiento frente a la soledad, brilla con luz propia la Europa del sur, representada por España e Italia. Tras mucho bregar con la tipología de los diez países observados, y tras controlar por la estructura demográfica, el nivel 
educativo y económico, el número de hijos, la incapacidad funcional y la coyuntura del momento de observación, no se ha conseguido desvelar las causas de la distancia en la relación de acompañamiento que, lejos de disminuir, se amplifica una vez se controla por todos estos factores.

En efecto, en el modelo final se presenta España como el país en que la relación de acompañamiento es mayor, siendo Dinamarca el lugar donde la misma es menor. Desde este polo de mínima relación de acompañamiento se sitúa la pareja formada por Suecia y Holanda, y a cierta distancia con otro salto cualitativo, Suiza. En un punto intermedio están Francia, Bélgica, Austria y Alemania (la Europa central). Finalmente, con una relación de acompañamiento notablemente superior están Italia y España.

La tentación de atribuir este hecho a su "familismo» es muy fuerte, y vendría avalado por la disparidad que se da en las actitudes hacia la solidaridad familiar sobre el apoyo a los mayores (Albertini y Kohli 2013). Se afirma así que, mientras que a los nórdicos les gusta vivir solos, a los meridionales les gusta vivir acompañados. Pero también es plausible pensar que, mientras que en los países socialdemócratas los servicios públicos les permiten vivir solos hasta que necesitan asistencia continuada ante una pérdida importante de autonomía funcional, la falta de estos obliga en el sur de Europa a convivir con otras personas. Algunos de los resultados obtenidos aportan evidencias que confirmarían esta última interpretación. El hecho de que 1) la limitación en las actividades instrumentales de la vida diaria sea el factor que mayor impacto tiene sobre la probabilidad de vivir acompañado, 2) de que se ve claramente un patrón en que a mayor nivel educativo, mayor ratio de hogares unipersonales, y de que 3) el aumento observado durante el período de crisis queda anulado por las dificultades funcionales y la disponibilidad de hijos, nos hace pensar que nos hallamos más ante una mayor libertad de elección en los países socialdemócratas que ante un supuesto «familismo» o necesidad de compañía en los del sur.

Por otro lado, el mayor número de hijos está claramente asociado a una mayor ratio de acompañamiento a partir de los tres hijos. Sin embargo, en la línea de Zueras (2014) es más probable vivir acompañado cuando se tiene un solo hijo que cuando se tienen dos. Este patrón sugiere que entre padres e hijos únicos se establecen unos lazos de solidaridad diferenciales, tal vez debido a un mayor sentido de responsabilidad que podría diluirse cuando son dos los descendientes, o bien a cuestiones más pragmáticas como el intercambio de recursos: asistencia y compañía a cambio del patrimonio que acabará ineludiblemente siendo para el único vástago.

Los patrones residenciales descritos parecen responder a la diversidad de regímenes de cuidado observados según su regulación en países nórdicos, donde la responsabilidad de asistir a los mayores es del Estado, y en los países del centro o meridionales, donde la obligación recae primordialmente sobre la familia (Stark 2005). Esto se refleja no solo en las pautas de institucionalización, muy superior en los países del norte (Fernández Carro 2013: 109), sino también en la composición de las redes de apoyo informal dentro del hogar, que en los países del sur está compuesta básicamente por familiares mientras que en los del centro y especialmente en los del norte participan también personas ajenas a la red familiar (Attias-Donfut, Ogg y Wolf 2005; Fernández Carro 2013). Por ejemplo en España, 8 de cada 10 mayores que reciben cuidados son atendidos por un familiar como cuidador principal, mayoritariamente el cónyuge o una hija, que generalmente reside en el mismo hogar; aunque desde los noventa se ha producido un aumento progresivo de la privatización del cuidado (Martínez 2011). La externalización de la asistencia a los mayores se expandió gracias al desarrollo de la conocida como ley de dependencia, a pesar de que alrededor de la mitad de las transferencias monetarias percibidas fueron destinadas a cuidados no profesionales provistos dentro del entorno familiar (ibíd.). Con todo, es de prever que la erosión de la protección social así como el aumento del desempleo tenga un impacto mayor 0 a más largo plazo en aquellos países donde la crisis está siendo más virulenta: una hipótesis que podrá ser verificada en posteriores ciclos de SHARE.

\section{Biblografía}

Abellán, Antonio et al. 2007. A propósito de las condiciones de vida de las personas mayores. Madrid: IMSERSO.

Albertini, Marco y Martin Kohli. 2013. "The generational contract in the family: an analysis of transfer regimes in Europe" European Sociological Review 29(4): 828-840.

Albertini, Marco, Martin Kohli y Claudia Vogel. 2007. "Intergenerational transfers of time and money in European families: common patterns-different regimes?" Journal of European Social Policy 17(4): 319-334.

Albertini, Marco y Anna Garriga. 2011. "The effect of divorce on parentchild contacts". European Societies, Vol. 13(2): 257-278. http://dx.doi.org/10.1080/14616696.2010.483002

Aquilino, William S. 1990. "The likelihood of parent-adult child coresidence: Effects of family structure and parental characteristics". Journal of Marriage and the Family, $52(2$ (May, 1990)): 405-419.

Attias-Donfut, Claudine, Jim Ogg y François-Charles Wolf (2005): "Family support." en Health, Ageing and Retirement in Europe. First Results from the Survey of Health, Ageing and Retirement in Europe, editado por A. Börsch-Supan, A. Brugiviani, H. Jürges, J. Mackenbach, J. Siegrist y G. Weber. Research Institute for the Economics of Aging: Mannheim.

Bishop, C E. 1986. "Living arrangements choices of elderly singles." Health Care Financing Review, 7(3): 65-73.

Daatland, Svein Olav y Ariela Lowenstein. 2005. "Intergenerational solidarity and the family-welfare state balance." European Journal of Ageing 2(3): 174-182. http://dx.doi.org/10.1007/ s10433-005-0001-1

De Jong Gierveld, Jenny, Helga de Valk y Marieke Blommesteijn. 2001. "Living arrangements of older persons and family support 
in more developed countries." en Population Bulletin of the United Nations. Living Arrangements of Older Persons: Critical Issues and Policy Responses, 42/43: 193-217.

Delbès, Christiane, Joëlle Gaymu y Sabine Springer. 2006. "Les femmes vieillissent seules, les hommes vieillissent à deux. Un bilan européen". Population Et Sociètès, 1: 419.

Fernández Carro, Celia. 2013. "Ageing in Place in Europe: a multidimensional approach to independent living in later life." Tesis doctoral, Departamento de Geografía, Universidad Autónoma de Barcelona.

Festy, Patrick y Jitka Rychtarikova. 2008. "Living conditions for the elderly in the late twentieth century." Pp. 41-70 en Future elderly living conditions in Europe, editado por J. Gaymu, P. Festy, M. Poulain y G. Beets. Paris: INED.

Hank, Karsten. 2005. Spatial proximity and contacts between elderly parents and their adult children: a European comparison. DIW-Diskussionspapiere, No. 510

Isengard, Bettina y Marc Szydlik. 2012. "Living apart (or) together? Corresidence of elderly parents and their adult children in Europe". Research on Aging, 34(4): 449-474. http://dx.doi. org/10.1177/0164027511428455

Kalmijn, Matthijs y Chiara Saraceno. 2008. "A comparative perspective on intergenerational support: responsiveness to parental needs in individualistic and familialistic countries". European Societies, 10(3): 479-508. http://dx.doi. org/10.1080/14616690701744364

Klevmarken, N. Anders, Bengt Swensson y Patrik Hesselius. 2005. "The SHARE sampling procedures and calibrated design weights." Pp. 28-37 en Health, Ageing and Retirement in Europe - Methodology, editado por Börsch-Supan, Axel y Hendrik Jürges (eds.). Mannheim: Research Institute for the Economics of Aging.

Kohli Martin, Harald Künemund y Jörg Lüdicke. 2005. "Family structure, proximity and contact", en Health, Ageing and Retirement in Europe. First Results from the Survey of Health, Ageing and Retirement in Europe, editado por A. Börsch-Supan, A. Brugiviani, H. Jürges, J. Mackenbach, J. Siegrist y G. Weber. Mannheim: Research Institute for the Economics of Aging.

lacovou, Maria. 2000. "Health, wealth and progeny: Explaining the living arrangements of older European women." Working Paper (Paper 8). Institute for Social and Economic Research, Essex University.

Martínez Buján, Raquel. 2011. "La reorganización de los cuidados familiares en un contexto de migracón internacional". Cuadernos de Relaciones Laborales, 29: 93-123.

Laferrère, Anne et al. 2013. "Entry into institutional care: predictors and alternatives" Cap. 22, Pp. 253-264 en Active ageing and solidarity between generations in Europe, editado por A. Börsch-Supan et al. Disponible en http://www.degruyter.com/view/product/185064

López Doblas, Juan. 2005. Personas mayores viviendo solas. La autonomía como valor en alza. Madrid: IMSERSO.

López Doblas, Juan y María del Pilar Díaz Conde. 2013. "La modernización social de la vejez en España." Revista Internacional de Sociología, 71(1): 65-89. http://dx.doi.org/10.3989/ris.2011.04.26

Mickus, Maureen, Manfred Stommel y Charles W. Given. 1997. "Changes in living arrangements of functionally dependent older adults and their adult children." Journal of Ageing Health, 9(1): 126143. http://dx.doi.org/10.1177/089826439700900107

Mutchler, Jan E. y Jeffrey A. Burr. 1991. "A longitudinal analysis of household and nonhousehold living arrangements in later life." Demography, 28(3):375-390. http://dx.doi.org/10.2307/2061463
Palloni, Alberto. 2001. "Living arrangements of older persons." en Population Bulletin of the United Nations. Living Arrangements of Older Persons: Critical Issues and Policy Responses, (42-43): 54-110.

Pampel, Fred C. 1992. "Trends in living alone among the elderly in Europe", Elderly Migration and Population Redistribution: 97-117.

Pérez Ortiz, L. 2006. La estructura social de la vejez en España. Nuevas y viejas formas de envejecer. Madrid: IMSERSO.

Pezzin, Liliana E. y Barbara S. Schone. 1999. "Parental marital disruption and intergenerational transfers: An analysis of lone elderly parents and their children". Demography, 36(3): 287297. http://dx.doi.org/10.2307/2648053

Rabe-Kesketh, Sophia y Anders Skrondal. 2008. Multilevel and Longitudinal Modeling Using Stata. Texas: Stata Press Publication.

Robine, Jean-Marie, Isabelle Romieu y Emmanuelle Cambois. 1999. "Health expectancy indicators". Bulletin of the World Health Organization, 77 (2): 181-185.

Speare Jr., Alder, Roger Avery y Leora Lawton. 1991. "Disability, residential mobility, and changes in living arrangements," Journal of Gerontology, 46(3): S133-S142.

Spitze, Glenna, John R. Logan y Joyce Robinson. 1992. "Family structure and changes in living arrangements among elderly nonmarried parents." Journal of Gerontology, 47(6): S289-S296.

Stark, Agneta. 2005. "Warm hands in cold age - On the need of a new world order of care." Feminist economics, 11(2): 7-36. http:// dx.doi.org/10.1080/13545700500115811

Worobey, Jacqueline L. y Angel, Ronald J. 1992. "Functional capacity and living arrangements of unmarried elderly persons." Journal of Gerontology, 45(3): S95-S101.

Zueras, Pilar y Marc Ajenjo Cosp. 2010. "Modelos de convivencia de las personas mayores en Cataluña. Impacto del deterioro de la salud en la independencia residencial". Revista Española de Geriatría y Gerontología, 45(5): 259-266. http://dx.doi. org/10.1016/j.regg.2010.04.009

Zueras, Pilar. 2014. "Disentangling age and cohort effects in coresidence with adult children among the elderly in Catalonia". Estadística Española, 56, no 184: 227-258.

Zueras, Pilar y Pau Miret. 2013. "Mayores que viven solos: una panorámica a partir de los censos de 1991 y 2001". Revista Española de Investigaciones Sociológicas, 144:139-152.

PAU MIRET GAMUNDI es investigador del Centre d'Estudis Demogràfics (CED) de la Universitat Autònoma de Barcelona (UAB). Licenciado en Sociología por la UAB en 1989, postgrado en Demografía en el CED en 1991 y doctorado por la UNED en 2002. Ha trabajado en el Reino Unido en el Cathie Marsh Centre for Census and Survey Research (Manchester) y en el Departamento de Estadísticas Sociales en la Universidad de Southampton. Ha sido investigador Ramón y Cajal en el Departamento de Geografía de la UAB (2005-2009). Sus principales áreas de interés son la sociología de las edades, la formación familiar y la dinámica del mercado de trabajo.

PILAR ZUERAS es investigadora del Centre d'Estudis Demogràfics, de la Universitat Autònoma de Barcelona. Licenciada en Sociología (2007) y doctora en Demografía (2014) por la Universitat Autònoma de Barcelona (UAB). Cursó la European Doctoral School of Demography (EDSD, 2011/12) y ha realizado estancias predoctorales en el Institut National d'Études Demogràfics (INED, París) y en el Max Planck Institute for Demographic Research (Rostock, Alemania). Su investigación se centra en el estudio de la población madura y mayor desde diversas dimensiones: la salud, el trabajo, la familia y la convivencia. 